\title{
Effect of Temperature on Severity of Fusarium Wilt of Lettuce Caused by Fusarium oxysporum f. sp. lactucae
}

\author{
J. C. Scott and T. R. Gordon, Department of Plant Pathology, and D. V. Shaw, Department of Plant Sciences, Uni- \\ versity of California, Davis, CA 95616; and S. T. Koike, University of California Cooperative Extension, Monterey \\ County, Salinas, CA 93901
}

\begin{abstract}
Scott, J. C., Gordon, T. R., Shaw, D. V., and Koike, S. T. 2010. Effect of temperature on severity of Fusarium wilt of lettuce caused by Fusarium oxysporum f. sp. lactucae. Plant Dis. 94:13-17.

The effect of temperature on Fusarium wilt of lettuce (Lactuca sativa), caused by Fusarium oxysporum f. sp. lactucae, was examined in a controlled environment. Nine lettuce cultivars planted in infested potting mix (500 or 5,000 CFU/g) were maintained under high/low diurnal temperature regimes of $26 / 18^{\circ} \mathrm{C}, 28 / 20^{\circ} \mathrm{C}$, or $33 / 26^{\circ} \mathrm{C}$. Three cultivars were resistant to Fusarium wilt under all test conditions, and thus were little affected by differences in inoculum level or temperature. The remaining cultivars were more susceptible and manifested more severe symptoms at the higher inoculum level and when maintained at higher temperatures. The tendency for the disease to be more severe under warmer conditions may be due, in part, to an effect of temperature on growth of the pathogen. Radial growth rates calculated for six isolates of F. oxysporum f. sp. lactucae were observed to increase from $10^{\circ} \mathrm{C}$ up to an apparent maximum near $25^{\circ} \mathrm{C}$. The results of this study suggest that growers can reduce the risk of damage from Fusarium wilt by avoiding susceptible cultivars during the warmest planting periods. Further, isolates of $F$. oxysporum f. sp. lactucae were shown to have a distinctive colony morphology in culture, which made it possible to distinguish them from nonpathogenic strains.
\end{abstract}

In 1967, Fusarium oxysporum f. sp. lactucae was proposed as a novel forma specialis for the pathogen causing a root disease affecting lettuce (Lactuca sativa L.) near Tokyo in Japan (19). Plants affected by this disease initially appear chlorotic and stunted. As the disease progresses, symptoms become more severe and may include death of older leaves or collapse of the entire plant. Internally, vascular tissue typically sustains a pinkish to red discoloration. This may be accompanied by extensive rotting of the taproot, which inspired the name "Fusarium root rot" $(6,19)$.

Since its discovery in Japan in 1955 (19), the disease has spread to all major lettuce-producing regions within that country $(7,32)$, where three races $(4,5,7)$ and three vegetative compatibility groups $(4,23)$ have been described. In California, this disease was first observed on the head lettuce cultivar Empire in the San Joaquin Valley (Fresno County) in the fall of 1990

Corresponding author: T. R. Gordon

E-mail: trgordon@ucdavis.edu

Accepted for publication 31 August 2009.

doi:10.1094/PDIS-94-1-0013

(C) 2010 The American Phytopathological Society and was referred to as Fusarium wilt (15). Fujinaga et al. demonstrated that Fusarium root rot and Fusarium wilt of lettuce were the same disease, attributable to a single causal agent: F. oxysporum f. sp. lactucae (4). This disease was identified in the Yuma lettuce production area in Arizona in 2001 (17), and in the Pajaro and Salinas valleys of California in 2003 (T. R. Gordon and J. C. Scott, unpublished observation). In addition to its occurrence in North America and Japan, Fusarium wilt of lettuce has been reported in Taiwan (14), Iran (21), Italy (9), and most recently in Portugal (24) and Brazil (31). Outside of Japan, all isolates of $F$. oxysporum $\mathrm{f}$. sp. lactucae tested thus far are race $1(10,20)$.

In Arizona, Fusarium wilt was initially reported in seven fields, but by 2005 the disease was known to occur in at least 27 distinct locations (18). All fields where Fusarium wilt was reported were established during the warmest (autumn) planting period (18). Likewise, in the Edogowa district of Japan, four cycles of lettuce were grown in a year, and Fusarium wilt was a problem in the spring, summer, and autumn plantings, but not in the cooler (winter) planting (19). The differential development of disease between planting periods may reflect an effect of temperature. Warmer temperatures also have been associated with more severe symptoms of
Fusarium wilt on other crops such as chickpea (2), spinach (3), muskmelon (26), banana (25), chrysanthemum (8), and carnation (1).

This study was undertaken to evaluate the effect of temperature on disease severity by testing lettuce cultivars known to differ in susceptibility to Fusarium wilt (27) under three temperature regimes and two inoculum levels. Additionally, a collection of isolates obtained from symptomatic plants and from soil was used to establish a correlation between colony morphology in culture and pathogenicity to lettuce. Finally, the effect of temperature on radial growth rates was characterized for six isolates of $F$. oxysporum $\mathrm{f}$. sp. lactucae (three from Arizona and three from California).

\section{MATERIALS AND METHODS}

Effect of temperature on disease severity. Seed of nine lettuce cultivars, consisting of three romaine (Caesar, Green Forest, and King Henry), two leaf (Lolla Rossa and Red Rossa), and four head (Early Queen, Grand Max, Kahuna, and Salinas) types were sown into potting mix infested with $F$. oxysporum f. sp. lactucae, as described below. One to three days after germination, seedlings were thinned to eight per pot, with two pots $(12.5 \times 12.5$ $\mathrm{cm}$, and $6 \mathrm{~cm}$ deep) per treatment. Plants were maintained in a controlled environment chamber (Conviron model PGR15, Pembina, ND) set to one of three high/low diurnal temperature regimes: $\operatorname{cool}\left(23 / 18^{\circ} \mathrm{C}\right)$, moderate $\left(28 / 20^{\circ} \mathrm{C}\right)$, or warm $\left(33 / 23^{\circ} \mathrm{C}\right)$, and a $14-\mathrm{h}$ photoperiod. After 1 month, plants were rated for symptom development on a 1 to 4 scale: $1=$ no symptoms, 2 $=$ mild stunting, $3=$ severe stunting and some leaf yellowing and/or necrosis, and 4 $=$ dead plants. Intermediate ratings, such as 1.5 or 2.5 , were used where appropriate. Because plants maintained under the cool temperature regime developed few disease symptoms within the first month, they were rated again 1 month later to determine if maintenance at the cooler temperature only slowed the rate of disease development.

Infested potting mix was prepared using isolate GL 1110 (=HL-2 of Hubbard and 
Gerik [15]) of F. oxysporum f. sp. lactucae. Cultures of GL 1110 growing on potato dextrose agar (PDA) were maintained for 14 to 21 days at room temperature $(21.4 \pm$ $0.9^{\circ} \mathrm{C}$ ) and then macerated in sterile deionized water (seven plates per $50 \mathrm{ml}$ ) using a blender (Waring Commercial 700 Model 31BL46, Torrington, CT). The resulting slurry of mycelium and spores was mixed with 1 liter of autoclaved sand and allowed to dry at room temperature for 5 to 7 days.

Dilution plating (27) was used to quantify inoculum densities in infested sand. Ten-gram samples were suspended in 200 $\mathrm{ml}$ of $1.0 \%$ sodium hexametaphosphate and stirred vigorously for $5 \mathrm{~min}$, at which point a $15-\mathrm{ml}$ subsample was transferred to $85 \mathrm{ml}$ of $0.1 \%$ water agar and stirred for an additional $5 \mathrm{~min} ; 500 \mu \mathrm{l}$ of the final $0.1 \%$ water agar suspension was spread onto each of 12 plates containing Komada's selective medium (KM) (16), which was modified from the original recipe by reducing the amount of pentachloronitrobenzene (99\%) from 1.0 to $0.2 \mathrm{~g} / \mathrm{liter}$. Additional 10 -fold dilutions were added to the dilution series as needed. Inoculated plates were maintained at room temperature under continuous fluorescent light $(24 \mathrm{~h} /$ day $)$ for 7 to 10 days, after which colonies of $F$. oxysporum f. sp. lactucae were identified based on their distinctive colony morphology, as described below.

Infested sand was blended into Premier Pro potting mix (Premier Horticulture Inc., Quakertown, PA) in the amounts needed to obtain two different inoculum densities: 5 $\times 10^{2}$ and $5 \times 10^{3} \mathrm{CFU} / g$ potting mix. The higher level was selected because severity of Fusarium wilt in lettuce cultivars grown at $5 \times 10^{3} \mathrm{CFU} / \mathrm{g}$ under controlled conditions is predictive of disease severity under high disease pressure in the field (27). The lower inoculum density was included to provide a comparative assessment under less severe disease pressure. Control plants, established from seed sown into noninfested sand blended with potting mix, were included in all assays at all three temperature regimes. A full experiment included two replicate pots of eight seedlings for each cultivar at two inoculum levels and three temperatures in a factorial design. This experiment was conducted twice.

Colony morphology and pathogenicity to lettuce. Isolates of $F$. oxysporum were obtained from lettuce plants and from soil in commercial fields in major lettuce production areas of California and Arizona (Table 1). Isolates from soil were obtained using dilution plating as described above. To obtain isolates from diseased plants, tissue segments taken from taproots were briefly dipped in $70 \%$ ethanol, submersed in $1 \%$ sodium hypochlorite for $2 \mathrm{~min}$, and cultured on plates of KM at room temperature under continuous fluorescent light (24 $\mathrm{h} /$ day). Spores removed from colonies identified as $F$. oxysporum on KM were streaked on water agar to obtain a single spore for each isolate, and single spore subcultures were stored on dried filter paper (12). Each isolate was cultured on $\mathrm{KM}$, and after 7 to 10 days of growth at room temperature under continuous fluo-

Table 1. Isolates used to test for a correlation between colony morphology of Fusarium oxysporum f. sp. lactucae on Komada's selective medium and pathogenicity to lettuce

\begin{tabular}{lllcr}
\hline Location $^{\mathbf{a}}$ & Year $^{\mathbf{b}}$ & Source $^{\mathbf{c}}$ & Pathogenic $^{\mathbf{d}}$ & Nonpathogenic $^{\mathbf{e}}$ \\
\hline Monterey Co., CA & 2002 & Lettuce & 10 & 0 \\
Monterey Co., CA & 2002 & Soil & 3 & 13 \\
Monterey Co., CA & 2003 & Lettuce & 5 & 0 \\
Monterey Co., CA & 2003 & Soil & 0 & 17 \\
Monterey Co., CA & 2005 & Lettuce & 33 & 15 \\
Monterey Co., CA & 2006 & Lettuce & 19 & 6 \\
Monterey Co., CA & 2007 & Lettuce & 18 & 3 \\
Monterey Co., CA & 2008 & Lettuce & 0 & 4 \\
Fresno Co., CA & 2002 & Lettuce & 15 & 4 \\
Fresno Co., CA & 2002 & Soil & 25 & 76 \\
Fresno Co., CA & 2003 & Lettuce & 2 & 0 \\
Yuma Co., AZ & 2001 & Lettuce & 12 & 0 \\
Yuma Co., AZ & 2002 & Lettuce & 15 & 0 \\
Yuma Co., AZ & 2002 & Soil & 20 & 33 \\
Yuma Co., AZ & 2003 & Lettuce & 3 & 3 \\
Yuma Co., AZ & 2005 & Lettuce & 0 & 3 \\
Yuma Co., AZ & 2006 & Lettuce & 6 & 0 \\
Italy & $\ldots$ & Lettuce & 3 & 0 \\
Japan & $\ldots$ & Lettuce & 3 & 0 \\
Taiwan & $\ldots$ & Lettuce & 4 & 0 \\
Totals & & & 196 & 177 \\
\hline
\end{tabular}

a The county and state wherein commercial lettuce production fields were located.

${ }^{\mathrm{b}}$ The year in which collections were made.

${ }^{c}$ Isolates were obtained either from soil or symptomatic lettuce plants.

${ }^{d}$ The number of isolates that induced symptoms of Fusarium wilt in lettuce seedlings subjected to a root dip assay.

${ }^{\mathrm{e}}$ The number of isolates that did not induce symptoms of Fusarium wilt in root-dip inoculated seedlings.

${ }^{\mathrm{f}}$ Collection year not known. rescent light, colony morphology was evaluated with respect to the density and architecture of aerial mycelium, and the pigmentation evident from above and on the underside of the colony.

Each isolate was tested for pathogenicity on lettuce seedlings in a root-dip assay. Aqueous suspensions of $5 \times 10^{6}$ spores per $\mathrm{ml} 0.5 \% \mathrm{KCl}$ were used to inoculate a known susceptible cultivar (Early Queen or New Dominion). Seedlings at the twoto three-leaf stage (13 to 18 days after emergence) were gently uplifted, and their roots were rinsed free of potting mix and trimmed to 4 to $8 \mathrm{~cm}$ in length. Roots were submerged in a spore suspension for 10 min, after which seedlings were transplanted into Premier Pro potting mix. Inoculated seedlings were maintained in a controlled environment chamber with a 14$\mathrm{h}$ photoperiod and day/night temperatures of $28 / 20^{\circ} \mathrm{C}$. Plants were rated 3 weeks later for symptom development on a 1 to 4 scale, as described above. A susceptible cultivar inoculated with the known pathogenic isolate GL 1110 was included in every test as a control.

Thirty-three isolates determined to be pathogenic on lettuce and representative of the geographic breadth of the collection were tested on differential cultivars to identify race, as described by McCreight et al. (20). Inoculated plants were maintained in a growth chamber and rated for disease severity as described above.

Radial growth temperature assay. The effect of temperature on radial growth was examined in six isolates of $F$. oxysporum $\mathrm{f}$. sp. lactucae obtained from symptomatic plants and confirmed to be pathogenic on lettuce: GL 1110, GL 1111, and GL 1112 from California, and GL 1113, GL 1114, and GL 1115 from Arizona. All isolates were grown on $2 \%$ water agar at room temperature for 5 to 7 days, at which time 5-mm-diameter plugs were removed from within $15 \mathrm{~mm}$ of the colony margin. Each plug was positioned at the center of a plate $(9 \mathrm{~cm}$ diameter) containing $1 / 2 \times$ PDA. Plates were placed in an incubator set at one of five constant temperatures $(10,15$, 20,25 , or $30^{\circ} \mathrm{C}$ ) without light. Because radial growth rates differed according to the incubation temperature, plates were examined at different time intervals for each temperature, as follows: after 6, 9, 15, 23 , and 33 days of incubation at $10^{\circ} \mathrm{C}$; after $3,6,8,9$, and 18 days at $15^{\circ} \mathrm{C}$; after $2,3,6$, and 7 days at $20^{\circ} \mathrm{C}$; after $1,3,4$, and 6 days at $25^{\circ} \mathrm{C}$; and after $1,2,4$, and 8 days at $30^{\circ} \mathrm{C}$. At each interval, three plates per isolate per temperature were removed from the incubator, and the diameter of the colony was measured to the nearest millimeter. Each plate was measured once and then discarded. A full experiment consisted of three replications of six isolates at five temperatures in a factorial design. The entire experiment was conducted three times. 
Data analysis. All analyses were conducted using SAS (release 9.1, SAS Institute, Cary, NC). Disease severity data were analyzed using Proc rank to obtain midranks followed by Analysis of Variance (ANOVA) using Proc mixed, as described by Shah and Madden (29). Radial growth rates were estimated as the slope of the line relating colony diameter to time of measurement using linear regression (Proc reg). Linear regression was also used to evaluate the effects of temperature on growth rate. The effect of isolate on the relationship between growth rate and temperature was examined by performing an analysis of covariance using Proc GLM.

\section{RESULTS}

Effect of temperature on disease severity. All plants grown in noninfested potting mix (controls) remained healthy at all temperatures for the duration of both experiments. For plants grown in infested potting mix, ANOVA indicated the main effects of cultivar, inoculum density, and temperature were significant $(P<0.001$ in all cases). The cultivar*temperature* inoculum density and temperature* inoculum density interactions were not significant $(P=0.396$ and 0.112 , respectively), but the cultivar*inoculum density and cultivar*temperature interactions were both significant $(P<0.001)$. Consequently, data were further analyzed by cultivar (Table 2).

The head lettuce cultivar Early Queen was highly susceptible and developed typical symptoms of stunting and dieback. Disease was most severe under warm conditions $\left(33 / 23^{\circ} \mathrm{C}\right)$ and least severe under cool conditions $\left(23 / 18^{\circ} \mathrm{C}\right)$; this was true at both 500 and 5,000 CFU/g (Fig. 1A and B). A two-way ANOVA showed the main effect of temperature on disease severity in Early Queen to be significant $(P<0.001)$, whereas the interaction between inoculum density and temperature was not significant $(P=0.980)$. The other three head lettuce cultivars (Kahuna, Grand Max, and Salinas) also developed more severe disease under warm conditions (Fig. 1A and B); in all cases the effect of temperature was significant $(P<0.001)$ and the interaction between temperature and inoculum density was not $(P \geq 0.071)$ (Table 2$)$.

Significant effects of temperature on disease severity were also detectable in three romaine cultivars: Green Forest, Caesar, and King Henry $(P \leq 0.026)$. These effects were more apparent at the higher inoculum density (Fig. 1A and B), but the inoculum density*temperature interaction was not significant $(P \geq 0.075)$.

Only in the leaf cultivars, Lolla Rossa and Red Rossa, was the effect of temperature not significant $(P \geq 0.051)$. Both of these cultivars were symptom-free or nearly so (mean disease rating $\leq 1.3$ ) under all test conditions (Fig. 1A and B). The effect of inoculum density on disease severity was not significant for these two cultivars but was for all other cultivars that were tested (Table 2).

Inoculated plants maintained under the cool temperature regime were re-examined 1 month after the initial rating to determine if low temperature only slowed development of disease. The increased incubation time did not significantly increase mean disease severity $(P \geq 0.240)$ for any of the tested cultivars.

Colony morphology and pathogenicity to lettuce. Three hundred and seventythree isolates were tested for pathogenicity to lettuce, and those that induced a mean disease severity rating $>2.5$ (on the 1 to 4 scale previously described) were classified as pathogenic. The colony morphology on KM associated with pathogenicity to lettuce was a pink pigmentation on the underside of the colony and white aerial mycelium that was organized into variously sized tufts (Fig. 2A). Of 196 isolates that were pathogenic to lettuce (Table 1), 195 $(99 \%)$ had this colony morphology. No isolates with this appearance were nonpathogenic on lettuce. Nonpathogenic isolates of $F$. oxysporum growing on KM had sparse aerial mycelium and lacked the pigmentation characteristic of $F$. oxysporum f. sp. lactucae (Fig. 2B). Thirtythree isolates found to be pathogenic to lettuce were tested on differential cultivars, and all were determined to be race 1 (data not shown).

Radial growth. All six isolates grew slowly at $10^{\circ} \mathrm{C}$, progressively more rapidly at higher temperatures up to $25^{\circ} \mathrm{C}$, and more slowly at $30^{\circ} \mathrm{C}$ than at $25^{\circ} \mathrm{C}$ (Fig. 3). Linear regression showed the effect of temperature (in the range of 10 to $25^{\circ} \mathrm{C}$ ) on radial growth rates to be significant and to account for nearly all the observed variation (Table 3 ). Analysis of covariance was used to determine if the relationship between temperature and growth rate differed among the isolates tested. The results showed the effect of isolate and the isolate*temperature interaction both to be nonsignificant $(P=0.894$ and 0.810 , respectively).

\section{DISCUSSION}

F. oxysporum is an anamorphic species comprised of numerous host-specific, pathogenic strains and nearly ubiquitous, nonpathogenic, root-colonizing strains (11). Based on the morphological criteria by which this species is defined (22), pathogenic strains cannot be reliably distinguished from those incapable of causing disease. However, for some formae speciales, colony morphology on a selective medium is distinctly different from that associated with nonpathogenic strains $(13,30)$. Our findings show this to be the case for $F$. oxysporum f. sp. lactucae as well, at least within the range of the pathogen in California and Arizona. Variation in the appearance of nonpathogenic strains might compromise this distinction in other lettuce growing areas.

Higher temperatures generally corresponded to greater severity of Fusarium wilt in lettuce, but the nature of the rela-

Table 2. Analysis of fixed effects on severity of Fusarium wilt in nine cultivars of lettuce

\begin{tabular}{llcrrr}
\hline Cultivar & Effect $^{\text {a }}$ & Numerator df & Denominator df & $\boldsymbol{F}$ value & $\boldsymbol{P}$ value \\
\hline Early Queen & Temp & 1 & 17 & 1.52 & 0.218 \\
Early Queen & ID & 2 & 17 & 205.94 & $<0.001$ \\
Early Queen & Temp*ID & 2 & 17 & 0.01 & 0.980 \\
Kahuna & Temp & 1 & 17 & 15.92 & $<0.001$ \\
Kahuna & ID & 2 & 17 & 32.82 & $<0.001$ \\
Kahuna & Temp*ID & 2 & 17 & 0.88 & 0.411 \\
Grand Max & Temp & 1 & 17 & 1.72 & 0.190 \\
Grand Max & ID & 2 & 17 & 11.98 & $<0.001$ \\
Grand Max & Temp*ID & 2 & 17 & 1.15 & 0.303 \\
Salinas & Temp & 1 & 17 & 15.61 & $<0.001$ \\
Salinas & ID & 2 & 17 & 19.82 & $<0.001$ \\
Salinas & Temp*ID & 2 & 17 & 0.73 & 0.419 \\
Green Forest & Temp & 1 & 17 & 9.21 & 0.002 \\
Green Forest & ID & 2 & 17 & 13.75 & $<0.001$ \\
Green Forest & Temp*ID & 2 & 17 & 2.84 & 0.075 \\
Caesar & Temp & 1 & 17 & 6.75 & 0.009 \\
Caesar & ID & 2 & 17 & 8.76 & 0.001 \\
Caesar & Temp*ID & 2 & 17 & 1.05 & 0.323 \\
King Henry & Temp & 1 & 17 & 2.54 & 0.1112 \\
King Henry & ID & 2 & 17 & 4.32 & 0.0255 \\
King Henry & Temp*ID & 2 & 17 & 0.66 & 0.4614 \\
Lolla Rossa & Temp & 1 & 17 & 0.69 & 0.406 \\
Lolla Rossa & ID & 2 & 17 & 3.45 & 0.051 \\
Lolla Rossa & Temp*ID & 2 & 17 & 0.17 & 0.747 \\
Red Rossa & Temp & 1 & 17 & 0.14 & 0.704 \\
Red Rossa & ID & 2 & 17 & 2.25 & 0.119 \\
Red Rossa & Temp*ID & 2 & 17 & 3.20 & 0.053 \\
\hline
\end{tabular}

${ }^{\text {a }}$ Temp $=$ temperature regime under which plants were incubated (cool, moderate, or warm); ID = inoculum density to which plants were exposed $\left(5 \times 10^{2}\right.$ or $5 \times 10^{3} \mathrm{CFU} / \mathrm{g}$ potting mix); and Temp*ID $=$ the interaction between temperature and inoculum density. 


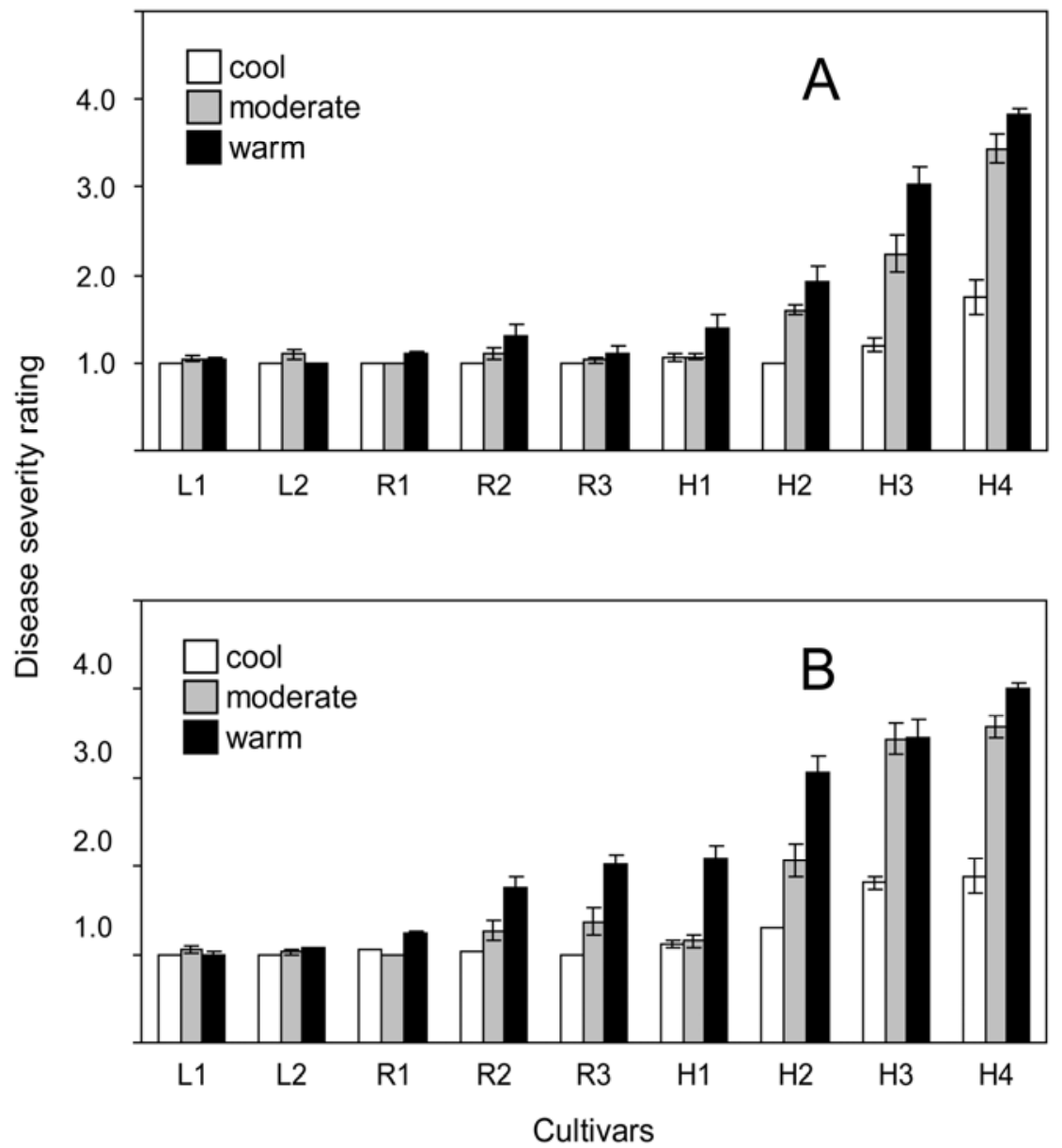

Fig. 1. Severity of Fusarium wilt on lettuce cultivars rated for disease symptoms (on a 1 to 4 scale) 1 month after being direct seeded into potting mix infested with Fusarium oxysporum $\mathrm{f}$. sp. lactucae at either A, $500 \mathrm{CFU} / \mathrm{g}$ or $\mathbf{B}, 5,000 \mathrm{CFU} / \mathrm{g}$. Plants were maintained under one of three temperature regimes: cool $\left(23 / 18^{\circ} \mathrm{C}\right)$, moderate $\left(28 / 20^{\circ} \mathrm{C}\right)$, or warm $\left(33 / 23^{\circ} \mathrm{C}\right)$. Cultivars are coded as follows: $\mathrm{L} 1=$ Lolla Rossa and L2 = Red Rossa (leaf types); R1 = King Henry, R2 = Caesar, and R3 = Green Forest (romaine types); and H1 = Grand Max, H2 = Salinas, H3 = Kahuna, and H4 = Early Queen (head types). Error bars represent $2 \times$ the standard error of the mean.

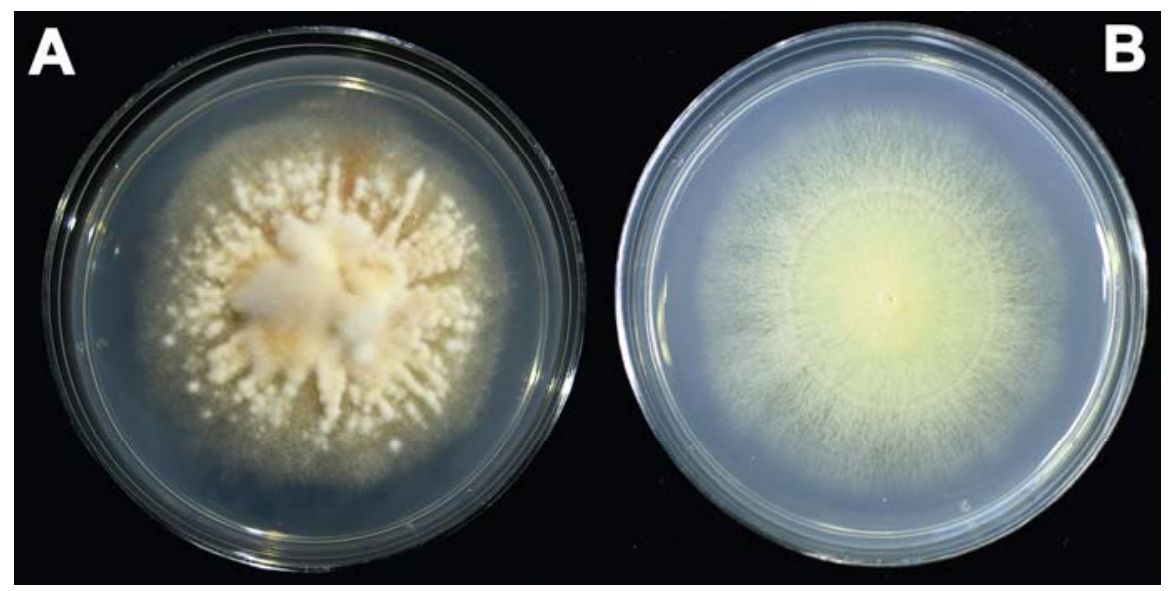

Fig. 2. Colony morphology of $\mathbf{A}$, Fusarium oxysporum f. sp. lactucae and $\mathbf{B}$, a nonpathogenic isolate of $F$. oxysporum growing on Komada's selective medium.

tionship was variable. For highly susceptible cultivars, the effect was dramatic. For example, at $500 \mathrm{CFU} / \mathrm{g}$, disease severity in Early Queen increased from $1.8 \pm 0.2$ when plants were maintained under cool conditions $\left(23 / 18^{\circ} \mathrm{C}\right)$ to $3.4 \pm 0.2$ under moderate conditions $\left(28 / 20^{\circ} \mathrm{C}\right)$. The latter rating would likely correspond to few or no marketable plants, and thus the increase in disease severity (to $3.8 \pm 0.1$ ) under warm conditions $\left(33 / 23^{\circ} \mathrm{C}\right)$ would be of no practical importance. On the other hand, for less susceptible cultivars, meaningful effects may be evident across a wider range of temperatures. This was apparent for Salinas, which manifested severity ratings of $1.3 \pm 0.1,2.1 \pm 0.2$, and $3.1 \pm$ 0.2 under cool, moderate, and warm conditions, respectively. For the most resistant cultivars, Lolla Rossa and Red Rossa (leaf types), an effect of temperature on disease severity was not detectable, even at the high inoculum level. Thus, the impact of temperature on Fusarium wilt of lettuce is clearly contingent on the cultivar, which helps to explain the significant interactions revealed by ANOVA in the overall analysis.

Our findings are consistent with results of studies conducted in Arizona, where modest differences in soil temperatures were associated with a significant effect of planting date on severity of Fusarium wilt in lettuce (18). Likewise, reports from Japan indicate that this disease is most severe during the warmest planting periods (19).

The basis for an effect of temperature on disease severity is not known but could be due, in part, to a direct effect on development of the pathogen. All isolates grew more rapidly at $25^{\circ} \mathrm{C}$ than at lower temperatures, and the optimum for growth presumably lies between 25 and $30^{\circ} \mathrm{C}$. Temperature may also influence disease severity through an effect on the host. The optimum temperature for growth of lettuce appears to be lower than $25^{\circ} \mathrm{C}$ (28), so higher temperatures may compromise the plant's ability to constrain development of the pathogen.

Because the effects of temperature are dependent on the cultivar being examined, it is not possible to develop a simple quantitative relationship between temperature and disease severity in lettuce. However, it is clear that a susceptible cultivar is likely to suffer greater damage when temperatures are higher. In California, lettuce is grown throughout the year so growers can exploit this effect of temperature on Fusarium wilt by not planting susceptible cultivars during the warmest planting periods. The effect of temperature on disease also has relevance to screening for resistance to Fusarium wilt. For example, when maintained under cool conditions, seven cultivars were essentially indistinguishable even at the high inoculum level, with disease severities ranging from 1.0 to 1.3 . In contrast, clear differences among these cultivars were apparent under warm conditions, as the range of disease severities expanded to 1.0 to 3.1. This suggests that higher resolution of differences in susceptibility can be obtained under warmer conditions, which should facilitate selection for resistance to Fusarium wilt. The romaine and leaf types included in this study are among the most resistant cultivars yet tested (27) and thus constitute a source of resistance that can be transferred to the more susceptible head lettuce cultivars. 


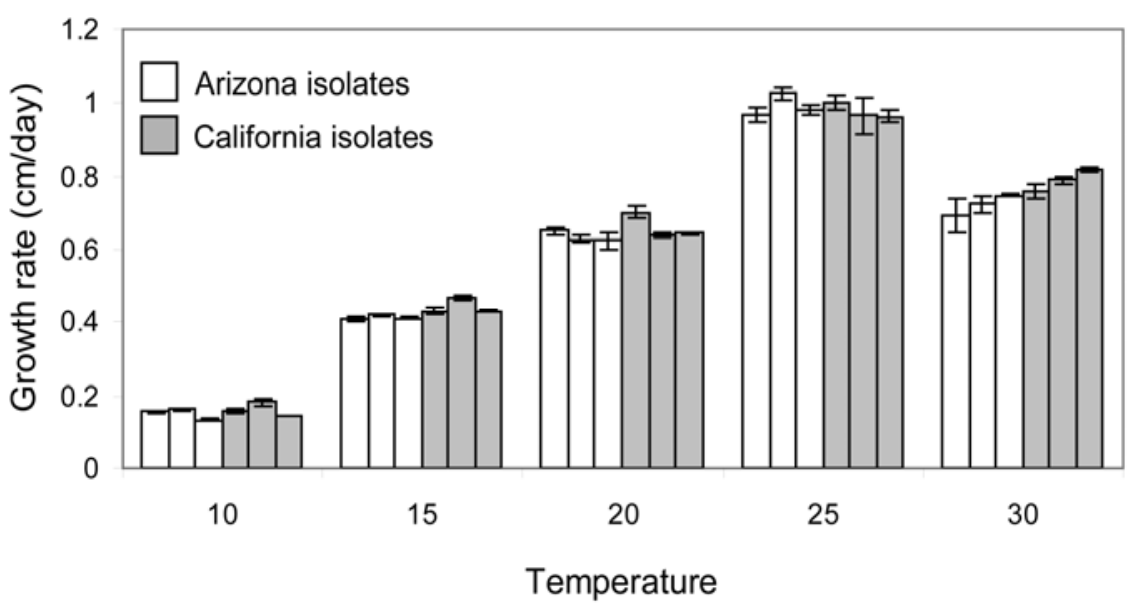

Fig. 3. Mean growth rates of six isolates of Fusarium oxysporum $\mathrm{f}$. sp lactucae grown on $1 / 2 \times$ potato dextrose agar (PDA) and incubated at one of five constant temperatures. At each temperature, isolates are displayed in the same order (left to right): GL 1114, GL 1113, GL 1115, GL 1110, GL 1111, and GL 1112. Error bars represent $2 \times$ the standard error of the mean.

Table 3. Results of linear regression of radial growth rates of Fusarium oxysporum f. sp. lactucae on temperature

\begin{tabular}{lcccc}
\hline Isolate & Origin $^{\mathbf{a}}$ & Slope $^{\mathbf{b}}$ & $\begin{array}{c}\text { Regression } \\
\text { coefficient }\left(\boldsymbol{R}^{\mathbf{2}}\right)\end{array}$ & $\boldsymbol{P}$ value \\
\hline GL 1110 & California & 0.059 & 0.998 & 0.0007 \\
GL 1111 & California & 0.054 & 0.995 & 0.0018 \\
GL 1112 & California & 0.058 & 0.992 & 0.0027 \\
GL 1113 & Arizona & 0.058 & 0.989 & 0.0038 \\
GL 1114 & Arizona & 0.058 & 0.996 & 0.0015 \\
GL 1115 & Arizona & 0.058 & 0.990 & 0.0034 \\
\hline
\end{tabular}

${ }^{a}$ Location of the lettuce production field from which the isolate was originally obtained.

${ }^{\mathrm{b}}$ Increase in radial growth rate (cm/day) per unit increase in temperature in the range of 10 to $25^{\circ} \mathrm{C}$.

\section{ACKNOWLEDGMENTS}

This research was supported, in part, by grants from the California Lettuce Research Board. The authors acknowledge technical assistance from Tom Kominek, Richard Webb, Laura Kong, Mana Ohkura, Brenna Aegerter, Ben Pavlik, Diana BurkhartWaco, Kat Kammeijer, and Patty Ayala, and helpful comments on earlier versions of this manuscript from Lynn Epstein and Mike Davis. The authors thank Belinda Platts, Jim Farrar, Jim McCreight, and Mike Davis for assistance in the collection of isolates. The authors thank Larry Madden for advice on the use of proc rank and proc mixed for the analysis of disease severity data and Beverly McFarland for help preparing figures.

\section{LITERATURE CITED}

1. Ben-Yephet, Y., and Shtienberg, D. 1994. Effects of solar radiation and temperature on Fusarium wilt in carnation. Phytopathology 84:1416-1421

2. Bhatti, M. A., and Kraft, J. M. 1992. Effects of inoculum density and temperature on root rot and wilt of chickpea. Plant Dis. 76:50-54.

3. Correll, J. C., Morelock, T. E., Black, M. C., Koike, S. T., Brandenberger, L. P., and Dainello, F. J. 1994. Economically important diseases of spinach. Plant Dis. 78:653-660.

4. Fujinaga, M. 2005. Studies on physiological races and phylogenetic analysis of lettuce root rot pathogen, Fusarium oxysporum f. sp. lactucae. J. Gen. Plant Pathol. 71:457.

5. Fujinaga, M., Ogiso, H., Shinohara, H., Tsushima, S., Nishimura, N., Togawa, M., Saito, H., and Nozue, M. 2005. Phylogenetic relationships between the lettuce root rot pathogen Fusarium oxysporum f. sp. lactucae races 1, 2, and 3 based on the sequence of the intergenic spacer region of its ribosomal DNA. J. Gen. Plant Pathol. 71:402-407.

6. Fujinaga, M., Ogiso, H., Tsuchiya, N., and Saito, H. 2001. Physiological specialization of Fusarium oxysporum f. sp. lactucae, a causal organism of Fusarium root rot of crisp head lettuce. J. Gen. Plant Pathol. 67:205-206.

7. Fujinaga, M., Ogiso, H., Tuchiya, N., Saito, H., Yamanaka, S., Nozue, M., and Kojima, M. 2003. Race 3, a new race of Fusarium oxysporum f. sp. lactucae determined by a differential system with commercial cultivars. J. Gen. Plant Pathol. 69:23-28.

8. Gardiner, D. C., Horst, R. K., and Nelson, P. E. 1987. Symptom enhancement of Fusarium wilt of chrysanthemum by high temperatures. Plant Dis. 71:1106-1109.

9. Garibaldi, A., Gilardi, G., and Gullino, M. L. 2002. First report of Fusarium oxysporum on lettuce in Europe. Plant Dis. 86:1052.

10. Garibaldi, A., Gilardi, G., and Gullino, M. L. 2004. Seed transmission of Fusarium oxysporum f. sp. lactucae. Phytoparasitica 32:6165 .

11. Gordon, T. R., and Martyn, R. D. 1997. The evolutionary biology of Fusarium oxysporum. Annu. Rev. Phytopathol. 35:111-128.

12. Gordon, T. R., and Okamoto, D. 1991. Vegetative compatibility groupings in a local population of Fusarium oxysporum. Can. J. Bot. 69:168-172.

13. Gordon, T. R., Okamoto, D., and Jacobson, D. J. 1989. Colonization of muskmelon and nonsusceptible crops by Fusarium oxysporum f. sp. melonis and other species of Fusarium. Phytopathology 79:1095-1100.

14. Huang, J. H., and Lo, C. T. 1998. Wilt of lettuce caused by Fusarium oxysporum in Tai- wan. Plant Pathol. Bull. 7:150-153.

15. Hubbard, J. C., and Gerik, J. S. 1993. A new wilt disease of lettuce incited by Fusarium oxysporum $\mathrm{f}$ sp. lactucum forma specialis nov. Plant Dis. 77:750-754.

16. Komada, H. 1975. Development of a selective medium for quantitative isolation of Fusarium oxysporum from natural soils. Rev. Plant Prot. Res. 8:114-125.

17. Matheron, M. E., and Koike, S. T. 2003. First report of Fusarium wilt of lettuce caused by Fusarium oxysporum f. sp. lactucae in Arizona. Plant Dis. 87:1265.

18. Matheron, M. E., McCreight, J. D., Tickes, B. R., and Porchas, M. 2005. Effect of planting date, cultivar, and stage of plant development on incidence of Fusarium wilt of lettuce in desert production fields. Plant Dis. 89:565-570.

19. Matuo, T., and Motohashi, S. 1967. On Fusarium oxysporum $\mathrm{f}$. sp. lactucae $\mathrm{n}$. f. causing root rot of lettuce. (Translated.) Mycol. Soc Jpn. 32:13-15.

20. McCreight, J. D., Matheron, M. E., Tickes, B R., and Platts, B. 2005. Fusarium wilt race 1 on lettuce. HortScience 40:529-531.

21. Millani, M. J., Etebarian, H. E., and Alizadeh, A. 1999. Occurrence of Fusarium wilt of lettuce in Shahre-Ray, Varamin, and Karaj areas. Iran J. Plant Pathol. 35:44-45.

22. Nelson, P. E., Toussoun, T. A., and Marasas, W. F. O. 1985. Fusarium Species: An Illustrated Manual for Identification. Pennsylvania State University, University Park.

23. Pasquali, M., Dematheis, F., Gilardi, G., Gullino, M. L., and Garibaldi, A. 2005. Vegetative compatibility groups of Fusarium oxysporum f. sp. lactucae from lettuce. Plant Dis. 89:237-240.

24. Pasquali, M., Dematheis, F., Gullino, M. L., and Garibaldi, A. 2007. Identification of Race 1 of Fusarium oxysporum f. sp. lactucae on lettuce by inter-retrotransposon sequence characterized amplified region technique. Phytopathology 97:987-996.

25. Peng, H. X., Sivasithamparam, K., and Turner, D. W. 1999. Chlamydospore germination and Fusarium wilt of banana plantlets in suppressive and conducive soils are affected by physical and chemical factors. Soil Biol. Biochem. 31:1363-1374.

26. Punja, Z. K., Parker, M., and Elmhirst, J. F. 2001. Fusarium wilt of field-grown muskmelon in British Columbia. Can. J. Plant Pathol. 23:403-410.

27. Scott, J. C., Kirkpatrick, S. C., and Gordon, T. R. Variation in susceptibility of lettuce cultivars to Fusarium wilt caused by Fusarium oxysporum f. sp. lactucae. Plant Pathol. In press.

28. Seginer, I., Shina, G., Albright, L. D., and Marsh, L. S. 1991. Optimal temperature set points for greenhouse lettuce. J. Agric. Eng. Res. 49:209-226.

29. Shah, D. A., and Madden, L. V. 2004. Nonparametric analysis of ordinal data in designed factorial experiments. Phytopathology 94:3343.

30. Smith, S. N., and Snyder, W. C. 1975. Persistence of Fusarium oxysporum f. sp. vasinfectum in fields in the absence of cotton. Phytopathology 65:190-196.

31. Ventura, J. A., and Costa, H. 2008. Fusarium wilt caused by Fusarium oxysporum on lettuce in Espirito Santo, Brazil. Plant Dis. 92:976.

32. Yamauichi, N., Horuchi, S., and Satuo, M. 2001. Pathogenicity groups in Fusarium oxysporum f. sp. lactucae on horticultural types of lettuce cultivars. J. Gen. Plant Pathol. 67:288-290. 